\title{
Влияние модификации порошкообразного хитозана на его аморфно-кристаллические и адсорбционно-порометрические характеристики
}

\author{
Седелкин В.М., Потехина Л.Н., Лебедева О.А., Ульянова Э.Р. \\ Энгельсский технологический институт (филиал) Саратовского государственного технического \\ университета имени Гагарина Ю.А., Энгельс
}

Поступила в редакцию 11.05.2018 г.

\author{
DOI: https://doi.org/10.17308/sorpchrom.2018.18/566
}

Исследовано влияние различных способов модификации высокомолекулярного порошкообразного крабового хитозана, используемого в качестве сырья для получения адсорбентов, флокулянтов, пленочных материалов, разделительных мембран различного функционального назначения, на его аморфно-кристаллические и адсорбционно-порометрические характеристики.

Ключевые слова: высокомолекулярный порошкообразный хитозан, модификация, аморфнокристаллические и адсорбционно-порометрические характеристики.

\section{Effect of modification of powdered chitosan on its amorphous-crystalline and adsorption-porometric characteristics}

\author{
Sedelkin V.M., Potehina L.N., Lebedeva O.A., Ulyanova E.R. \\ Engels Technological Institute (branch) of the Saratov State Technical University named after Yuri Gagarin, \\ Engels
}

The subject of the study was a high molecular weight powdered crab chitosan that does not dissolve in aqueous media, has a high sorption and film-forming ability and is a promising raw material for the production of adsorbents, flocculants, and film and membrane materials. The aim of the work was to identify the effect of chitosan modification by swelling in water vapor or reprecipitation from solutions with alkalis followed by freeze-drying to amorphous-crystalline and adsorption-porometric characteristics. For the study, granulometric, X-ray diffraction, sorption-structural analysis methods were used.

The structure and properties of the initial chitosan and its modified forms are studied in detail. It is shown that the investigated high-molecular crab chitosan is a partially crystalline polymer. Using the method of low-temperature sorption of liquid nitrogen, adsorption isotherms for the initial air-dried and lyophilized chitosan dried after equilibrium swelling with water vapor were obtained. Sorption and porometric characteristics are calculated.

It was found that the powdered chitosan studied is a mesoporous material with a range of pore radii from 1.5 to $45 \mathrm{~nm}$. The distribution of the integral and differential values of the volume and the specific surface of pores along the radii is analyzed. A comparative analysis of the obtained results showed that reprecipitation from the solution and a freeze-drying method of chitosan lead to a rearrangement of its supramolecular structure with a decrease in the degree of crystallinity from 0.5 to $0.1-0.22$. As a result of amorphization and loosening of the polymer matrix, the proportion of fine pores and the internal specific surface increases, the number of primary adsorption centers increases and their availability. It was found that the freeze-drying of the re-precipitated chitosan leads to a significant increase in its adsorption capacity. 
The use of the proposed methods for modifying chitosan allows us to significantly intensify the adventive processes when it is used as sorbents and flocculants, to accelerate its solvation in the preparation of solutions, and also opens up possibilities for regulating the selective transport characteristics of the chitosan separation membranes.

Keywords: high molecular weight powdered chitosan, modification, amorphous-crystalline and adsorption-porometric characteristics.

\section{Введение}

Хитозан (ХТ3) является наиболее простым и доступным производным продуктом природного полиаминосахарида - хитина и получается путем его частичного дезацетилирования. Благодаря наличию в макромолекулах хитозана активных гидроксильных и аминогрупп он сравнительно легко поддается физико-химической модификации, что позволяет влиять на его структуру и свойства как перспективного сырья для получения сорбентов, флокулянтов, пленочных материалов и разделительных мембран различного функционального назначения.

В работах $[1,2]$ показано, что для модификации хитозана с целью увеличения его пористости, внутренней удельной поверхности, сорбционной емкости, ослабления межмолекулярных связей и воздействия на надмолекулярную структуру можно использовать целый ряд способов воздействия.

Разработаны и исследованы способы модификации хитозана, основанные на набухании полимера в жидких органических веществах, обладающих сродством к полисахаридам, достаточно высокой полярностью и нуклеофильностью (жидкие алифатические амины и амиды, диметилформамид, диметилсульфоксид) [3,4]. Однако эти способы имеют существенный недостаток, связанный с необходимостью удаления агента набухания многократным инклюдированием полимера в менее полярных растворителях с последующей его сушкой.

Для модификации хитозана применяются также размол в виброшаровых или ударных мельницах, в шнековых экструдерах [5]. Однако при использовании данных способов происходит существенная деструкция макромолекулярных цепей и снижение молекулярной массы полимера, повышение энергоемкости процесса.

Наиболее простыми и дешевыми являются такие способы модификации хитозана, как его набухание в парах воды или переосаждение из раствора ХTЗ в кислотах раствором щелочей с использованием различных методов сушки $[1,2]$.

В работах [3,6] показано, что за счет модификации хитозана можно существенно улучшить его сорбционные характеристики к различным сорбируемым веществам. Однако в упомянутых работах изучались специфические формы хитозана (гранулы и полые микросферы), а также отсутствуют сведения об аморфнокристаллических и адсорбционно-порометрических параметрах.

Авторами [7-9] исследована надмолекулярная структура нативного порошкообразного хитозана, полученного из краба и криля. Установлено, что этот аминополисахарид состоит из кристаллической и аморфной частей, то есть является аморфно-кристаллическим полимером. Причем, кристаллическая фаза полимерной матрицы ХТЗ характеризуется полиморфизмом. В зависимости от происхождения хитозана и условий его получения параметры надмолекулярной структуры (число и расположение кристаллических рефлексов на рентгенодифрактограмме, размеры кристаллитов, степень кристалличности и др.) могут меняться. Поэтому для каждой модификации хитозана требуется уточнение специфики формирования его аморфнокристаллической структуры.

В данной работе приведены результаты исследования структуры и свойств исходного и модифицированного порошкообразного хитозана. 


\section{Эксперимент}

Для исследования был использован высокомолекулярный хитозан, который в водных средах только ограниченно набухает, но не растворяется. Исходный хитозан из камчатского королевского краба имел следующие характеристики: средневязкостная молекулярная масса $\bar{M}_{\eta}=420 \pm 10$ кДа, степень дезацетилирования СД $=80 \pm 2 \%$, насыпная плотность $\rho_{\mathrm{H}}=0.274$ г $/ \mathrm{cm}^{3}$, относительная влажность $\varphi=12.1 \%$. Хитозановый порошок имел полидисперсный состав и состоял из частиц с размерами от 0.2 до 2.0 мм, которые обладали полимодальностью распределения по размерам. Основными являлись две фракции с размерами частиц (1-1.5) мм и (0.45-0.63) мм, содержание которых в навеске составляло соответственно 32 и $28 \%$.

Для модификации хитозана использовали его набухание в водяных парах, а также переосаждение из водноуксуснокислого раствора щелочью $(\mathrm{NaOH})$ и содой $\left(\mathrm{NaHCO}_{3}\right)$. При этом исследование структуры и свойств исходного и модифицированного хитозана проводили для образцов, высушенных при комнатной температуре (воздушно-сухих) и в лиофильной сушилке.

В качестве одного из методов модификации исходного порошкообразного хитозана было использовано его набухание в водяных парах, которые в отличие от азота, являются неинертным сорбатом, с последующей лиофильной сушкой порошка. Исследование набухания хитозана в парах воды проводилось при температуре $25 \pm 2^{\circ} \mathrm{C}$. Обработка навески порошка хитозана водяными парами велась в герметичном сосуде, частично заполненном водой. Над поверхностью жидкости на сетчатом фильтре размещалась навеска порошка хитозана, подвергаемая паровой обработке.

Количество поглощенных порошком водяных паров определялось путем взвешивания навески ХТЗ после и до набухания. Степень набухания $\alpha$ полимерного сырья вычислялась по выражению:

$$
\alpha=\frac{m-m_{0}}{m_{0}} \times 100 \%,
$$

где $\mathrm{m}_{0}$ и $\mathrm{m}$ - масса навески до и после набухания соответственно, г.

Второй метод модификации хитозана состоял в следующем. Из исходного порошкообразного хитозана готовился низкоконцентрированный $\left(\mathrm{C}_{\mathrm{XT} 3}=0.5-1.0\right.$ мас.\%) водноуксуснокислый раствор. Затем путем обработки раствора щелочью $\mathrm{NaOH}$ или содой $\mathrm{NaHCO}_{3}$ из него получали переосажденный хитозан.

Для исследования были использованы три образца переосажденного хитозана. Первый образец был получен переосаждением щелочью $\mathrm{NaOH}$ и высушен на воздухе при температуре $25 \pm 2^{\circ} \mathrm{C}$. Второй образец был получен переосаждением щелочью $\mathrm{NaOH}$ и высушен лиофильно. Третий образец был переосажден содой $\mathrm{NaHCO}_{3}$ и высушен лиофильно.

Аморфно-кристаллические параметры хитозана определялись рентгеноструктурным методом, реализованным с использованием дифрактометра «ДРОН-3». Порометрические характеристики порошкообразного ХТЗ определялись по изотермам адсорбции азота и водяных паров, а также с использованием кинетических кривых набухания хитозана в водяных парах. Влажность ХТЗ определялась по стандартной методике, а насыпная плотность - гравиметрически с использованием электронных весов с ценой деления $10^{-4}$ г.

Изотермы адсорбции азота для порошкообразного хитозана получали с использованием быстродействующего компьютеризованного анализатора удельной поверхности и размера пор «Quantachrome NOVA 1200е». Образцы исследуемого порошка ХТЗ предварительно дегазировались под вакуумом при температуре $150^{\circ} \mathrm{C}$ в течение двух часов. Определение общего объема $\mathrm{V}_{\text {п }}$ и удельной поверхности $\mathrm{S}_{\text {уд }}$ 
пор, их радиусов $\mathrm{r}_{\text {п }}$, а также построение дифференциальных кривых распределения объемов пор и удельной поверхности по радиусам проводилось с использованием метода БЭТ [11].

\section{Обсуждение результатов}

На рис. 1 приведена дифрактограмма для исходного порошкообразного воздушно-сухого хитозана. Видно, что она представляет собой аморфное гало, на котором можно выделить четыре дискретных кристаллических рефлекса с максимума при углах $2 \Theta$ равных 19.35, 21.77, 28.5 и 33.4 градусов.

Анализ кристаллических рефлексов показал, что они отличаются большой угловой полушириной. Данный факт свидетельствует о микрокристаллической структуре полимера. Расчет размер кристаллитов для всех зафиксированных рефлексов, проведенный по классической формуле Дебая-Шеррера [10]

$$
L_{\kappa p}=\lambda(\beta \times \cos 2 \Theta)^{-1},
$$

показал, что эти размеры составляют $22-45 \AA$. В формуле (2) $\lambda$ - длина волны излучения, равная $1.54 \AA$; $\beta$ - полуширина пика, град; $2 \Theta$ - угол рефлекса, град.

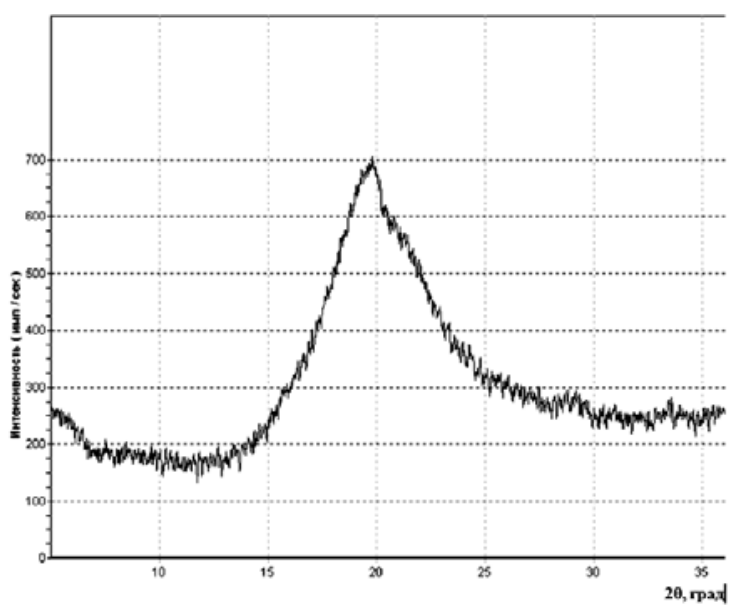

Рис. 1. Дифрактограмма порошкообразного хитозана

С использованием данных по интенсивности рассеяния рентгеновских лучей, приведенных на рис. 1, была вычислена степень кристалличности К воздушносухого хитозана, которая количественно характеризует соотношение закристаллизованной и аморфной частей полимера. Значение степени кристалличности оказалось равным 0.5 .

На рис. 2 приведена изотерма адсорбции азота для исходного порошкообразного хитозана, которая имеет вид, характерный для полукристаллических полимеров. Видно, что начальный участок изотермы, на протяжении которого происходит формирование адсорбционного мономолекулярного слоя объемом $\mathrm{V}_{\mathrm{m}}$, заканчивается в начальной точке линейного участка изотермы. Эта точка соответствует завершению образования монослоя при относительном давлении $\mathrm{P} / \mathrm{P}_{0}$, равном примерно 0,1 . Видно также, что начальный участок изотермы имеет вогнутость относительно оси давлений. Это свидетельствует о высоком уровне сродства адсорбента (порошка ХТЗ) даже к инертному адсорбату (азоту).

Полученная изотерма адсорбции имеет также протяженное плато в диапазоне $\mathrm{P} / \mathrm{P}_{0}=0.1-0.7$. Это свидетельствует о том, что хитозан является адсорбентом, в кото- 
ром доступная для адсорбции поверхность увеличивается пропорционально количеству адсорбированного вещества. При этом число свободных адсорбционных центров остается постоянным в широкой области относительных давлений сорбата, так как по мере заполнения одних центров появляются новые.

В общем процессе адсорбции линейный участок изотермы соответствует образованию и постепенному нарастанию полимолекулярного адсорбционного слоя. Интенсивность увеличения объема полимолекулярного слоя характеризуется тангенсом угла наклона линейного участка изотермы к оси абсцисс.

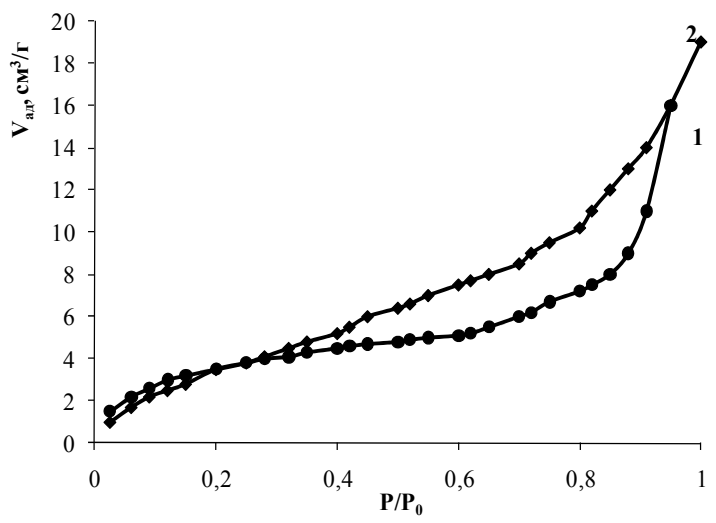

Рис. 2. Изотермы адсорбции для исходного воздушно-сухого (1) и лиофильно-высушенного (2) хитозана

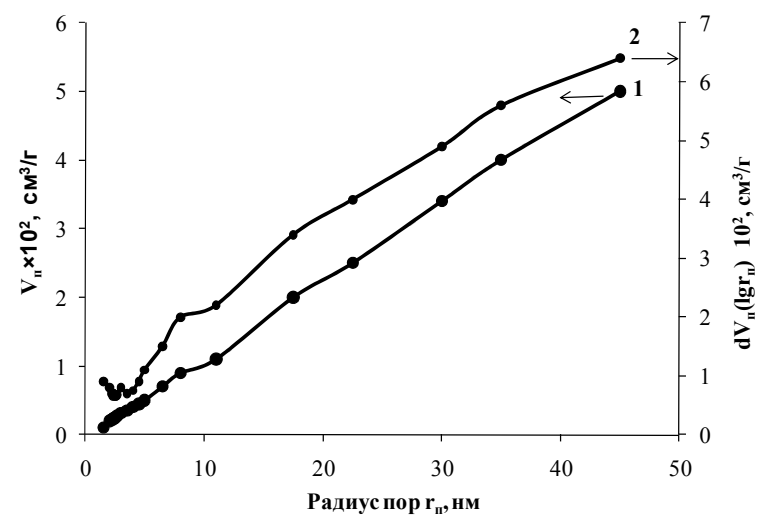

Рис. 3. Распределение интегрального (1) и дифференциального (2) объема пор по радиусам для исходного воздушносухого хитозана

При относительном давлении $\mathrm{P} / \mathrm{P}_{0}>0.7$ на изотерме адсорбции начинает формироваться третий участок, характерными особенностями которого являются вогнутость в сторону оси ординат и чрезвычайно крутой подъем. Эти особенности свидетельствуют о том, что третий участок изотермы соответствует последней стадии адсорбционного процесса - заполнению пор по механизму капиллярной конденсации.

Как видно из рис. 2, примерно $80 \%$ адсорбируемого вещества приходится на капиллярную конденсацию и только $20 \%$ - на моно- и полимолекулярную адсорбцию. На основании этих данных можно говорить о том, что для адсорбционных процессов, происходящих в порошкообразном воздушно-сухом хитозане, механизм капиллярной конденсации играет определяющую роль.

Используя представления метода БЭТ [11] на основе изотермы адсорбции были рассчитаны параметры, входящие в уравнение БЭТ (количество сорбата $\mathrm{V}_{\mathrm{m}}$, покрывающего всю поверхность монослоем, константа С, характеризующая энергию адсорбции в монослое и являющаяся показателем магнитуды взаимодействия адсорбент - адсорбат), а также теплота адсорбции монослоя $\mathrm{E}_{1}$. Значения этих параметров составили: $\mathrm{V}_{\mathrm{m}}=2.7 \mathrm{~cm}^{3} / \Gamma$;

$$
\mathrm{C}=86.34 ; \mathrm{E}_{1}=8.44 \text { кДж/моль. }
$$

На рис. 3 приведены интегральная и дифференциальная кривые распределения объема пор по их радиусам для исходного воздушно-сухого хитозана. Прежде всего, следует отметить, что исследованный порошкообразный ХТЗ является мезопористым сырьем с диапазоном изменения радиусов пор от 1.5 до 45 нм. Изменение удельного объема пор практически линейно связано с их радиусами. Интегральная пористость $\mathrm{V}_{\text {п }}$ не превышает $0.05 \mathrm{~cm}^{3} /$ г. На рис. 4 показано распределение интегральной и дифференциальной удельной поверхности пор по радиусам для исходного ХТЗ. Видно, что основной вклад в развитие удельной поверхности вносят поры с

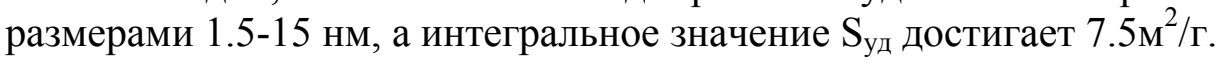


На рис. 5 приведена зависимость степени набухания воздушно-сухого порошкообразного хитозана в парах воды от времени с начала процесса. Анализ кинетики процесса показал, что в первый период набухание происходит с максимальной скоростью, а затем темп поглощения водяных паров падает. Максимальная (равновесная) степень набухания, равная 55\%, достигается через 10 суток. Однако после 12 часов процесс набухания протекает очень медленно. Поэтому точкой равновесия можно считать время, соответствующее $\alpha=52 \%$. Следует отметить, что при расчете текущих значений степени набухания учитывалась начальная влажность хитозана, равная $12.1 \%$.

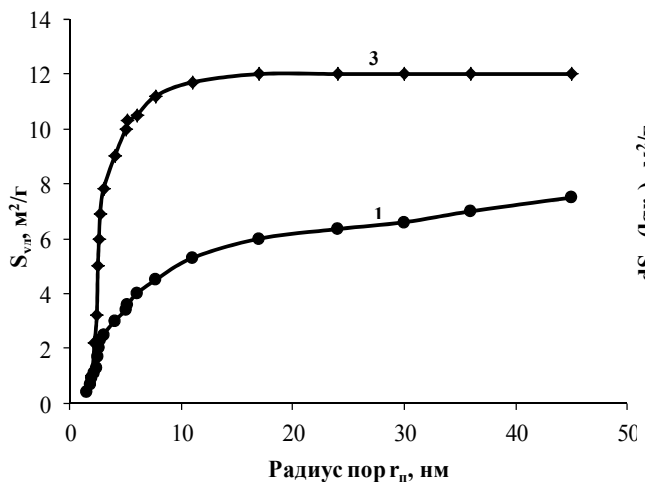

a

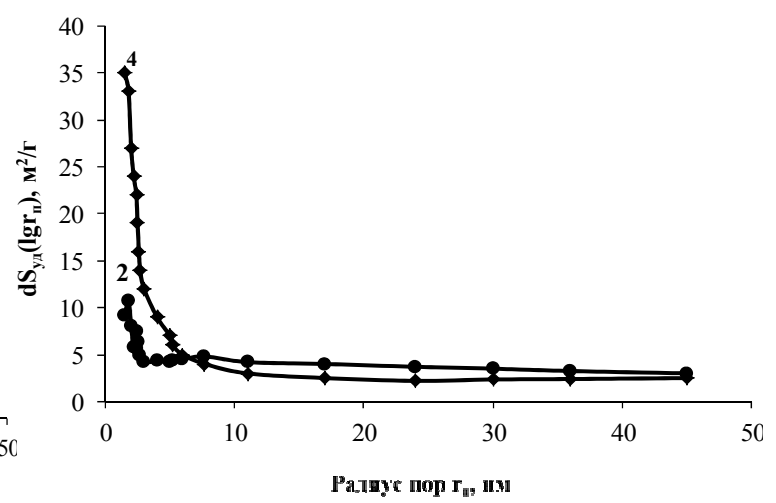

6

Рис. 4. Распределение интегральной $(1,3)$ и дифференциальной $(2,4)$ удельной поверхности пор хитозана по радиусам (1, 2- воздушно-сухой, 3,4 - лиофильно-высушенный)

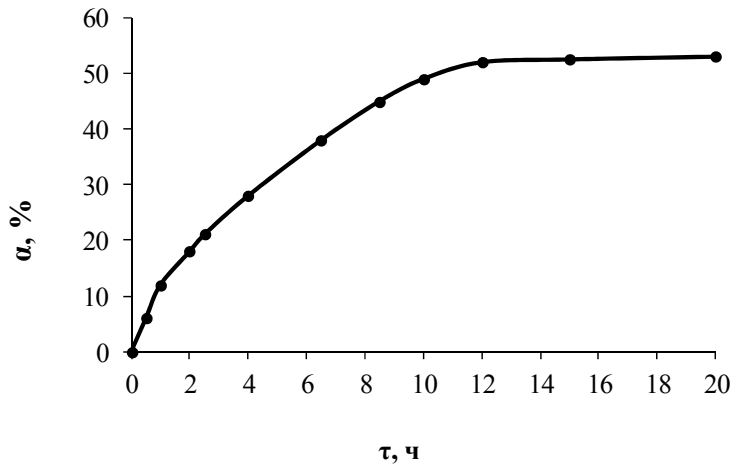

Рис. 5. Кинетика набухания исходного порошкообразного хитозана в парах воды

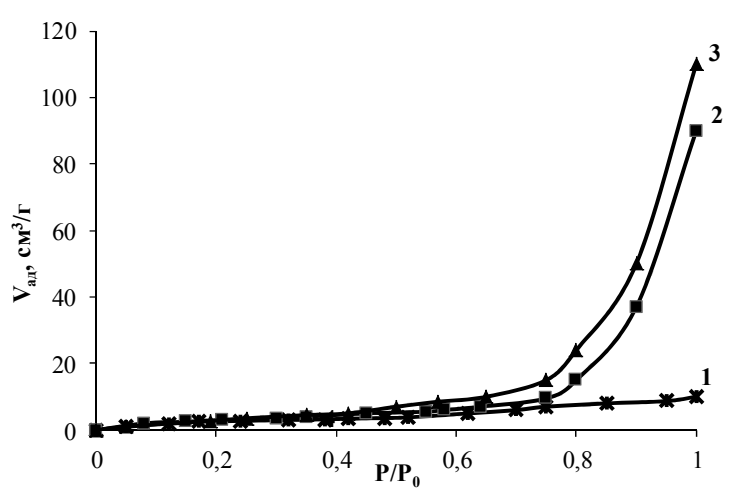

Рис. 6. Изотермы адсорбции паров воды для порошкообразного хитозана, переосажденного из водноуксуснокислых растворов щелочью с сушкой на воздухе (1) и лиофильно (2), переосажденного содой с сушкой лиофильно (3)

Для набухшего в парах воды и лиофильно высушенного порошка хитозана также были определены адсорбционно-порометрические характеристики. Изотерма адсорбции азота для порошка хитозана, прошедшего лиофильную сушку, приведена на рис. 2. Сравнение полученной изотермы с изотермой для воздушно-сухого хитозана показывает, что форма обеих кривых одинакова. Однако интенсивность адсорбционных процессов на различных участках обеих изотерм различна.

На начальном участке кривой адсорбции $\left(\mathrm{P} / \mathrm{P}_{0}<0.1\right)$, где формируется мономолекулярный адсорбционный слой, его объем на лиофильно высушенном порошке 
несколько меньше объема на исходном порошке. Это расхождение можно объяснить тем, что для лиофильно высушенного порошка хитозана удельная поверхность примерно на $30 \%$ больше, чем у воздушно-сухого порошка. На втором участке изотермы, напротив, прирост объема адсорбата происходит более высокими темпами для лиофильно высушенного порошка хитозана, что подтверждается бо́льшим углом наклона этой изотермы к оси абсцисс. Объяснением этого эффекта являются установленные полидисперсионные изменения, происходящие под воздействием лиофильной сушки с распределением пор по их радиусам. В лиофильно высушенном порошке появляется большое количество мелких мезопор с большей удельной поверхностью (рис. 4), что ускоряет процесс формирования полимолекулярного адсорбционного слоя, происходящий на этом участке изотермы.

На третьем участке изотермы, соответствующем заполнению пор по механизму капиллярной конденсации, объем сорбата составляет примерно $50 \%$ от общего объема адсорбированного вещества. Для воздушно-сухого хитозана объем сорбата на третьем участке доходил до $80 \%$.

Исходя из полученных результатов, можно сделать вывод, что модификация хитозана путем лиофильной сушки повышает в комплексном процессе физической адсорбции роль моно- и полимолекулярной адсорбции по сравнению с капиллярной конденсацией. Формирование моно- и полимолекулярных адсорбционных слоев в этом случае происходит интенсивнее, чем в варианте воздушно-сухого хитозана.

Линейная аппроксимация изотермы адсорбции азота для лиофильно высушенного порошка ХТЗ позволила вычислить параметры, входящие в уравнение БЭТ, значения которых составили $\mathrm{V}_{\mathrm{m}}=2.45 \mathrm{~cm}^{3} / \Gamma ; \mathrm{C}=24.84 ; \mathrm{E}_{1}=7.63$ кДж/моль.

Рентгеноструктурное исследование переосажденных из водноуксуснокислых растворов образцов хитозана показало, что их надмолекулярная структура отличается значительно большей аморфизацией по сравнению со структурой исходного ХТЗ. Степень кристалличности для них при переосаждении щелочью оказалась равной 0.11 - для сушки на воздухе, 0.18 - для лиофильной сушки и 0.22 - при переосаждении содой и лиофильной сушке. Полученные величины значительно ниже этого параметра для исходного хитозана. Видимо разрушенные в растворе кристаллиты исходного хитозана не успевают вновь сформироваться в ходе получения переосажденной форы ХТЗ, так как для кристаллизации необходимы соответствующие термодинамические, кинетические и стерические условия.

Увеличение степени кристалличности (упорядоченности) хитозана при его лиофильной сушке можно объяснить тем, что при криогенном замораживании равновесно набухшего хитозанового геля, осажденного при изменении $\mathrm{pH}$ раствора, структура матрицы геля жестко фиксируется. При последующем удалении влаги из образца путем возгонки льда непосредственно из твердого состояния в газообразное, минуя жидкую фазу, конформационные изменения макромолекул затрудняются, что препятствует дальнейшему разупорядочению его надмолекулярной структуры.

На рис. 6 приведены изотермы адсорбции паров воды для трех образцов хитозана, полученных переосаждением из раствора и высушенных в различных условиях. Видно, что лиофильная сушка переосажденного хитозана приводит к значительному увеличению его адсорбционной емкости. Причем, на величину сорбционного объема влияет также химический состав среды, с помощью которой происходит переосаждение хитозана из раствора. Удельные объемы адсорбированных паров воды для лиофильно высушенных образцов хитозана достигают $85-110 \mathrm{~cm}^{3} / \Gamma$, что превышает значение аналогичного параметра для воздушно-сухого образца.

Анализ полученных результатов показал, что основное влияние на интенсификацию адсорбционных процессов для переосажденного порошкообразного хито- 
зана оказывают условия его сушки. При лиофильной сушке во фронте сублимации замороженной влаги в условиях вакуума объем парообразной среды значительно возрастает, что приводит к образованию взрывной квазиударной волны. Под воздействием этой волны происходит разрыхление кристаллических и особенно аморфных надмолекулярных структур хитозана, увеличение их пористости и внутренней удельной поверхности с появлением дополнительных адсорбционных центров для неинертного сорбата (водяных паров), образованных лиофильными гидроксильными и аминогруппами. Все это приводит к различиям в адсорбционных характеристиках хитозана, высушенного лиофильно и в обычных условиях на воздуха.

\section{Заключение}

За счет использования предложенных методов модификации хитозана можно существенно активизировать адсорбционные процессы при его применении в качестве сорбентов и флокулянтов, ускорить сольватацию ХТЗ при приготовлении его растворов и регулировать селективно-транспортные характеристики хитозановых разделительных мембран.

\section{Список литературы}

1. Гальбрайх Л.С. // Соросовский образовательный журнал. 2001. Т. 7. № 1. С.51-56.

2. Пестов А.В. // Хитозан: сборник статей. М. Центр «Биоинженерия» РАН. 2013. С. 222-270.

3.Куприна Е.Э. // Хитин и хитозан. Получение, свойства и применение: сборник статей. М. Наука. 2002. С. 91-111.

4. Красавцева В.Е. // Хитозан: сборник статей. М. Центр «Биоинженерия» РАН. 2013. C. $14-48$.

5. Акопова Т.А., Роговина С.З., Горбачева И.Н., Вихорева Г.А. и др. // Высокомолекулярные соединения. 1996. Т. 38. № 2. С.263268.

\section{References}

1. Galbraich L.S., Soros Educational Journal, 2001, Vol .7, No 1, pp. 51-56.

2. Pestov A.V., Chitozan: collection of articles, M., Center "Bioengineering" RAS, 2013, pp. 222-270.

3. Kuprina E.E., Chitin and chitosan. Getting, properties and application: collection of articles, M., Nauka, 2002, pp. 91-111.

4. Krasavtseva V.E., Chitozan: collection of articles, M., Center "Bioengineering" RAS, 2013, pp. 14-48.

5. Akopova T.A., Rogovina S.Z., Gorbacheva I.N., Vikhoreva G.A. et al., Vysokomolekulyar-
6. Смирнов М.А., Агеев Е.П., Котельникова Т.А., Вихорева Г.А. // Структура и динамика молекулярных систем. 2003. Вып. 10. Ч. 2. C. $230-233$.

7. Могилевская Е.А., Акопова Т.А., Зеленецкий А.Н., Озерин А.Н. // Высокомолекулярные соединения. 2006. Т. 48. № 2. С. 216226.

8. Kozo O., Tochifume Y., Kenji O. // Int. J. Biol. Macromol. 2004. Vol. 34. pp.1-8.

9. Yui T., Kobayashi H., Kitamura S., Imada K. // Biopolymers. 1994. Vol.34. pp. 203-210.

10. Гинье А. Рентгенография кристаллов. М. Наука. 1961.549 с.

11. Грег С. Адсорбция, удельная поверхность, пористость. М. Мир. 1984. 334с.

nye soedineniya, 1996, Vol. 38, No 2, pp. 263268.

6. Smirnov M.A., Ageev E.P., Kotel'-nikova T.A., Vikhoreva G.A., Struktura i dinamika molekulyarnykh system, 2003, Vyp. 10, P. 2, pp. 230-233.

7. Mogilevskaya E.A., Akopova T.A., Zelenetskiy A.N., Ozerin A.N., Vysokomolekulyarnye soedineniya, 2006, Vol. 48, No 2, pp. 216226.

8. Kozo O., Tochifume Y., Kenji O., Int. J. Biol. Macromol., 2004, Vol. 34, pp. 1-8. 
9. Yui T., Kobayashi H., Kitamura S., Im-ada K., Biopolymers, 1994, Vol. 34, pp. 203-210.

10. Gin'e A. Rentgenografiya kristallov, M., Nauka, 1961, 549 p.

Седелкин Валентин Михайлович - профессор кафедры «Технология и оборудование нефтегазовых, химических и пищевых производств», д.т.н., Энгельсский технологический институт (филиал) Саратовского государственного технического университета имени Гагарина Ю.А., Энгельс

Потехина Лариса Николаевна - доцент кафедры «Оборудование и технологии обработки материалов», к.т.н., Энгельсский технологический институт (филиал) Саратовского государственного технического университета имени Гагарина Ю.А., Энгельс

Лебедева Ольга Александровна - аспирант кафедры «Технология и оборудование нефтегазовых, химических и пищевых производств», Энгельсский технологический институт (филиал) Саратовского государственного технического университета имени Гагарина Ю.А., Энгельс

Ульянова Эльмира Рушановна - аспирант кафедры «Технология и оборудование нефтегазовых, химических и пищевых производств», Энгельсский технологический институт (филиал) Саратовского государственного технического университета имени Гагарина Ю.А., Энгельс
11. Greg S., Adsorbtsiya, udel'naya poverkhnost', poristost', M., Mir, 1984, 334 p.

Sedelkin Valentin M. - Professor of the Department "Technology and Equipment of Oil and Gas, Chemical and Food Production", Doctor of Engineering Science, Engels Technological Institute (branch) of Saratov State Technical University named after Gagarin Yu.A., Engels

Potekhina Larisa N. - Associate Professor of the Department "Equipment and Materials Processing Technologies", Ph.D., Engels Technological Institute (branch) of Saratov State Technical University named after Gagarin Yu.A., Engels

Lebedeva Olga A. - post-graduate student of the department "Technology and equipment of oil and gas, chemical and food industries", Engels Technological Institute (branch) of Saratov State Technical University named after Gagarin Yu.A., Engels

Ulyanova Elmira R. - post-graduate student of the department "Technology and equipment of oil and gas, chemical and food industries", Engels Technological Institute (branch) of Saratov State Technical University named after Gagarin Yu.A., Engels 